\title{
The protective effect of Scenedesmus dimorphus polysaccharide as an antioxidant and antiaging agent on aging rat model induced by D-galactose
}

\author{
Armaini Armaini*, Imelda Imelda \\ Department of Chemistry, Faculty of Mathematics and Natural Science, Andalas University, Padang, Indonesia.
}

\section{ARTICLE INFO \\ Received on: 09/07/2020 \\ Accepted on: 17/01/2021 \\ Available online: 05/05/2021}

\section{Key words:}

Scenedesmus dimorphus, polysaccharides, antiaging, antioxidant, D-galactose

\begin{abstract}
Premature skin aging occurs due to the increased formation of reactive oxygen species (ROS), which causes oxidative stress, DNA damage, and collagen degradation. This study investigates the protective effect of Scenedesmus dimorphus polysaccharides (SDP) as an antioxidant and anti-aging agent on an aging rat model induced by D-galactose (D-gal). This study used 48 male Wistar rats divided into six groups: (1) normal control, (2) polysaccharide control, (3) aging control induced by D-gal $0.25 \mathrm{mg} / \mathrm{g}$ bw/days, (4) drug control (vitamin E) treated twice with SDP in an aging rat model, (5) D-gal + SDP (0.2 mg/g bw), and (6) D-gal + SDP $(0.8 \mathrm{mg} / \mathrm{g} \mathrm{bw})$ treated with oral treatment and observed for periods of 2, 4, and 8 weeks. Giving SDP at a dose of $0.8 \mathrm{mg} / \mathrm{g}$ bw can increase superoxide dismutases and catalase activity and reduce malondialdehyde after 8 weeks of observation, which is better than giving vitamin E. The treatment of SDP can stimulate collagen synthesis and reduce advanced glycation end products. Histopathology shows an increase in the area of fibrocollagen proportions and deposition from the matrix on giving SDP, which is better than vitamin E, since SDP can repair skin tissue. Thus, SDP can be useful as an antioxidant and anti-aging agent in an aging Wistar rats model.
\end{abstract}

\section{INTRODUCTION}

Manifestations of aging are characterized by the appearance of wrinkles, decreased tension and elasticity, skin thickness, hyperpigmentation, changes in skin color, telangiectasis, and a reduction in the water-binding capacity of the skin. Some of the biochemical reactions that trigger changes in the skin that lead to aging are (1) the emergence of reactive oxygen species (ROS), (2) the enzyme metalloproteinase [matrix metalloproteinase (MMP)] which is free activated, which decreases biosynthesis, and (3) collagen which leads to the final advanced glycation product (Mc Auley et al., 2017). MMP activation causes tissue degradation in the dermis that is controlled by enzymes when activated. These MMP includes collagenase, which is a group of enzymes that function to break down various types of collagen and elastin,

"Corresponding Author

Armaini Armaini, Department of Chemistry, Biochemistry Laboratory, Faculty of Mathematics and Natural Science, Andalas University. Padang. Indonesia.E-mail:armaini59@gmail.com; armaini@sci.unand.ac.id such as collagenase 1 (MMP-1) which acts on collagens I, II, III, VII, and X. Collagen becomes smaller. Fragments are degraded by MPP-1 which spontaneously transformed into peptide gels; this is then broken down by other MMPs. MMP has important activities to repair connective tissue, heal wounds, and improve aging (Sanz, 2006).

The skin is damaged by biochemical changes caused by the aging process, such as the appearance of wrinkles and spots, loss of elasticity and firmness, and inflammation and thinning of the skin matrix. The main biochemical imbalance is an increase in the activity of the collagenase, elastase, and hyaluronidase enzymes. This imbalance causes accelerated degradation of three main components of the skin: collagen (protein responsible for providing firmness), elastin (protein that gives elasticity), and hyaluronic acid (a type of glycosaminoglycans), which provide volume due to water retention (Dikalov and Harrison, 2014). Exposure to skin aging due to sunlight (photoaging) can cause changes to the three skin compartments: primary changes to the dermis and secondary changes to the epidermis and hypodermis.

Oxidative stress causes damage to cell structures due to environmental pressure, resulting in a dramatic increase in 
ROS which is a major cause of aging and several degenerative diseases. Based on the results of the research that has been carried out, skin damage can be caused by ultraviolet (UV) rays and lipid peroxidation as impact increased ROS, resulting in destruction to cell membranes which causes premature aging, skin cancer, and cell death (Dikalov and Harrison, 2014). Protein oxidation, lipid peroxidation, and injured mitochondria and DNA by oxidative stress and proinflammation due to an increase in ROS will inhibit normal cell function and cause apoptosis (Li et al., 2018; Schieber and Chandel, 2014). ROS directly or indirectly destroys endogenous antioxidant systems, including superoxide dismutase (SOD), catalase (CAT), and glutathione peroxidase (GSH-Px) (Zhao et al., 2017).

Microalgae polysaccharides consist of three types of polysaccharides, namely exo- or extracellular polysaccharide, sulfated polysaccharide, and polysaccharide which are composed of the main sugars, namely glucose, xylose, mannose, galactose, fructose, rhamnose, and several other compounds such as betaglucan, fucoidans, hyaluronic acid, and chondroitin sulfates. Hyaluronic acid content is a linear polysaccharide built by disaccharide units binding $\mathrm{N}$-acetyl-D-glucosamine and glucuronic acid. Hyaluronic acid has unique viscoelastic properties, which are influenced by the characteristics of polymers and polyelectrolytes (Kogan et al., 2007).

Polysaccharide (PS) biological and pharmacological activity is a complex interaction of several structural features, namely degree of sulfation, distribution of sulfate groups along the polysaccharide backbone, molecular weight, and composition of sugar residues (Zhong et al., 2019). PS from macro- and microalgae has been known to have biological activity; namely (i) it enhances immunity and (ii) contributes to anti-inflammation associated with downregulation of NF-j $\beta$ in the nucleus and inhibition of proinflammatory modulators including IL-1b, IL-6, tumour necrosis factor, and cyclooxygenase-2 (Hwang et al., 2011).

Fucoidan (sulfate polysaccharide) from brown algae, actively acts on the migration and proliferation of fibroblasts and modulates connective tissue proteolysis, and modulates connective tissue proteolysis. According to Thomas and Kim (2013), in vitro fucoidan can block expression of MMP-1 caused by UVBinduction by suppressing extracellular signal-regulated kinases and suppressing MMP-3 induction in skin fibroblasts. Also, ex vivo results show that fucoidan can minimize the activity of human leukocyte elastase, which results in the protection of skin elastic fiber tissue against enzymatic proteolysis (Wang et al., 2015).

Polysaccharides are beneficial to the skin as antiaging, anti-irritation, wound-healing, moisturizing, skin-firming, and anti-inflammatory agents; they also stimulate collagen synthesis, lock in natural moisture, strengthen the immune system, and act as antioxidants. The inhibitory effect of polysaccharide compounds on the activity of hyaluronidase and elastase enzymes, which plays a role in the aging process, is quite large. In vitro studies of polysaccharide sulfates obtained from the marine microalgae Porphyridium cruentum show that polysaccharide sulfates can be used as active ingredients in cosmetic and pharmaceutical formulations to maintain skin health and appearance. The natural polysaccharide extracted from Porphyridium has strong antiaging characteristics, as it shows significant inhibitory activity against two enzymes, namely hyaluronidase and elastase enzymes (Kenny et al., 2012). Polysaccharides contain beta-glucans, which are active immunostimulators, and have beneficial effects as antidotes to free radicals and reduce blood lipids (Chu et al., 2010). This research aims to study the protective effect of the Scenedesmus dimorphus polysaccharides (SDPs) as antioxidants and antiaging agents on aging rat models due to D-galactose (D-gal).

\section{MATERIALS AND METHODS}

\section{Materials and chemical}

Microalgae $S$. dimorphus collection of the Biochemical Laboratory, Department of Chemistry, Andalas University, D-gal (purity $\geq 99 \%$ ) and vitamin E (purity 95\%) were purchased from Sigma-Aldrich (St. Louis, MO). Vitamin E was dissolved in distilled water containing $1 \%$ Tween 80 solution. Lipid peroxidase (MDA) assay kit and superoxide dismutase assay kit were purchased from Abcam USA. CAT assay kit, Sirius Red, hematoxylin, xylene, and advanced glycation end products (AGEs) PromoKine Assay Kit were purchased from Elabscience.

\section{Instrumentation}

We used the following: ultrasonic bath (Krisbow DSA50GL, $40 \mathrm{kHz}$ ), spectrophotometer UV/Vis (Spectronic Genesys 20 Visible), centrifuge (Nasco 2,000-12,000 rpm), freeze drying equipment (Biobase-BK FD12S), fluorescence spectrophotometer (JASCO FP-6500) with a Peltier thermostat (JASCO, Easton, $\mathrm{MD}$ ), and ImageJ $1.49 \mathrm{v}$ software, National Institute of Health, Bethesda, MD.

\section{Experimental design}

The experiment was arranged in a randomized block design, comprising six groups with eight rats each: (1) normal control (NC), (2) polysaccharide control (PC), (3) aging control induced orally by D-gal $(0.25 \mathrm{mg} / \mathrm{g}$ bw/days), (4) drug control (vitamin E), (5) aging rats treated with low-dose polysaccharides (D-gal + SDP $0.2 \mathrm{mg} / \mathrm{g} \mathrm{bw}$ ), and (6) high-dose polysaccharides (D-gal + SDP $0.8 \mathrm{mg} / \mathrm{g}$ bw) orally treated. Observations were made at intervals of 2,4 , and 8 weeks.

\section{Extraction and purification of SDPs}

The ultrasonic method was used to extract the polysaccharide $S$. dimorphus. The biomass extraction procedure was immersed in distilled water $(130 \mathrm{w} / \mathrm{v})$ in a flask that was placed into an ultrasonic cleaning bath (preheated at $60^{\circ} \mathrm{C}, 24$ minutes with $300 \mathrm{~W}$, and incubated at $90^{\circ} \mathrm{C}, 2$ hours). The cell debris extract from the polysaccharides was removed by centrifuge. To concentrate the polysaccharide solution, a rotary evaporator was used and was precipitated with four volumes of $95 \%(v / v)$ ethanol for 24 hours at $4^{\circ} \mathrm{C}$. The precipitate was separated by centrifugation (10,000 g/minutes, 15 minutes), and the associated protein was released by trichloroasetic acid and the SDP crude extract was freeze-dried (Wei et al., 2005).

\section{Collecting blood}

Blood specimens of Wistar rats were separated between serum and erythrocytes using centrifugation $(5,000 \mathrm{~g})$ for 30 minutes. Blood was collected from the neck veins under deep anesthesia and drawn using a blood tube, for analysis of SOD, CAT, MDA, and fluorescent-advanced glycation end products (F-AGEs) (Armaini et al., 2020). 


\section{In vivo enzymatic antioxidant activity test}

Enzymatic antioxidant activity was determined by the colorimetric method; an SOD assay was carried out using an SOD Assay Kit (Abcam code ab.65354), a CAT (hydrogen peroxidase) assay was carried out using CAT Assay Kit (Elabscience, code E-BC-K102-S), and a lipid peroxidase assay was carried out using an MDA Assay Kit (Abcam code ab. 233471).

\section{Measurement of F-AGEs}

F-AGEs were measured with the spectrofluorometry method, using an AGE PromoKine Assay Kit. The wavelength of excitation is $360 \mathrm{~nm}$ and emission is $460 \mathrm{~nm}$. The blanks used were phosphate buffer saline solutions. Fluorescence intensity is calculated in arbitrary units per milliliter $(\mathrm{AU} / \mathrm{ml})$ and total protein in $\mathrm{AU} / \mathrm{g}$, and the Biuret method was used for determining total protein.

\section{Hydroxyl radical scavenging activity}

A $1 \mathrm{ml}$ SDP solution with various concentrations $(0.4$, $0.8,1.2,1.6$, and $2.0 \mathrm{mg} / \mathrm{ml})$ was prepared, and $1 \mathrm{ml}$ of FeSO4 (9 $\mathrm{mM}), 1 \mathrm{ml}$ of salicylic acid and ethanol $(9 \mathrm{mM})$, and $1 \mathrm{ml} \mathrm{H} 2 \mathrm{O} 2(9$ $\mathrm{mM}$ ) were added and mixed and incubated at $37^{\circ} \mathrm{C}$ for 30 minutes. Their absorbance was measured at $510 \mathrm{~nm}$. Distilled water in the same volume replaced the sample used as the control group.

The hydroxyl radical scavenging activity was expressed as follows:

Scavenging rate of

hydroxyl radical $\left(\mathrm{OH}^{*}\right)(\%)=\left(\left[\boldsymbol{A}_{0}-\boldsymbol{A}_{1}\right] / \boldsymbol{A}_{0}\right) \times 100$,

where $A_{0}$ is the absorbance of the control group and $A_{1}$ is the absorbance of the sample.

\section{Determination of superoxide radicals scavenging activity}

The superoxide radical $\left(\mathrm{O}_{2}{ }^{-}\right)$scavenging activity of SDP was determined using Halliwell's method with some modifications. The sample was prepared with a volume of $4 \mathrm{ml}$ and then $2.5 \mathrm{ml}$ of Tris- $\mathrm{HCl}$ buffer $(50 \mathrm{mM}, \mathrm{pH} 8.2)$ and $0.6 \mathrm{ml}$ pyrogallol $(25$ $\mathrm{mM}$ ) were added and mixed and incubated at $25^{\circ} \mathrm{C}$ for 5 minutes. $\mathrm{HCl} 1 \mathrm{ml}$ was added to stop the reaction and the absorbance was measured at $560 \mathrm{~nm}$.

Scavenging activity was calculated based on the following formula:

Scavenging rate of

superoxide radical $\left(\mathrm{O}_{2}{ }^{-}\right)(\%)=\left(\left[\boldsymbol{A}_{0}-\boldsymbol{A}_{1}\right] / \boldsymbol{A}_{0}\right) \times 100$,

where $A_{1}$ is the absorbance of the sample and $A_{0}$ is the standard absorbance (water not $\mathrm{H}_{2} \mathrm{O}_{2}$ ); ascorbic acid was used as a positive control.

\section{Histopathological preparation procedures of rat skin tissue}

The skin on the back of the rats was taken using an incisional biopsy technique, using a scalpel to make an incision. The rat was anesthetized using ether, an incision biopsy size of approximately $0.5 \mathrm{~cm}$ square was made, and the biopsy tissue was processed into histological preparation.

\section{Staining procedure with Sirius Red}

Rat skin tissue was fixed with $10 \%$ formalin and then processed into paraffin blocks. Paraffin blocks of $4 \mathrm{~mm}$ thickness were cut with a rotary microtome and placed on the slide. Blocks were deparaffinized with xylene $(2 \times 5$ minutes $)$ and rehydrated with multilevel alcohol, beginning with $100 \%$ ethanol, followed by $96 \%$ and then $70 \%$, and distilled water, for 5 minutes each. The preparation was stained with hematoxylin for 8 minutes, rinsed with aquadest for 10 minutes, and then soaked in a Sirius Red solution in saturated picric acid for 1 hour. Subsequently, it was rinsed in acidified water $(2 \times 5$ minutes $)$ and dehydrated in graded alcohol, with $70 \%, 96 \%$, and $100 \%$ ethanol, for 5 minutes each. Clearing in xylene $2 \times 5$ minutes, the glass deck was mounted with Entellan.

\section{Assessment procedure}

The fibrocollagen matrix was red due to the coloration with Sirius Red. Measurement of the fibrocollagen matrix area was carried out by taking photomicrographs at $100 \times$ magnification (objective $10 \times$ ) in five different fields. The red-stained area was measured using the Image J program (ImageJ $1.49 \mathrm{v}$ software, National Institute of Health, Bethesda, MD), by isolating the red color in Sirius Red staining and calculating the proportion of pixels colored red compared to the total pixel unit area. The proportion of fibrocollagen matrix area was reported in percent.

\section{Statistical analysis}

The data expressed are mean \pm standard deviation; sample $(n=8)$ at $p<0.05$ was considered statistically significant. Statistical analysis was made using analysis of variance (ANOVA) (with two factors with replication) of Microsoft Excel 2016. Estimates of animal friction or mortality in this study expect a reduction of $10 \%$.

\section{RESULTS}

\section{Enzyme activity of SOD}

Wistar rats induced by the D-gal group experienced an increase in ROS, which resulted in aging. Increased ROS resulted in a decrease in SOD activity of D-gal-induced rats compared to that of normal rats (NC). The activity of SOD enzymes in the body was higher in rats administered with SDP than in NC and drug control (vitamin E). The result of the SOD enzyme activity test in each treatment can be seen in Table 1. The administration of SDP for 2-8 weeks caused a significant increase in SOD activity compared with SOD activity in NC and rats administered with vitamin E. Statistical tests with ANOVA at $p<0.05$ showed significant differences in each treatment group. Aging rats treated with vitamin $\mathrm{E}$ displayed a higher increase in SOD enzyme activity than that of $\mathrm{NC}$ at 8 weeks of observation time.

\section{Enzyme activity of CAT}

Wistar rats induced by D-galactose caused ROS levels to high in the body so that it can reduce the activity of CAT enzymes and cause oxidative stress. Decreased CAT is triggered by an increase in ROS, which is observed 2-8 weeks after the D-gal treatment. In this study, the results of the CAT enzyme activity test in all treatment groups were observed for 2-8 weeks as shown in Table 2 . The data obtained showed that rats administered with SDP for 2-8 weeks displayed a higher increase in the activity of CAT enzymes than the $\mathrm{NC}$ and rats administered with vitamin $\mathrm{E}$ as a drug control. An SDP dose of 
$0.8 \mathrm{mg} / \mathrm{g}$ bw for 8 weeks is an effective dose to increase CAT activity. Analysis of variances at $p<0.05$ showed significant differences among treatment groups, $\mathrm{NC}$ and aging control (group treated with D-gal).

\section{Enzyme activity of malondialdehyde (MDA)}

Increased MDA activity was observed in aging control due to the induction by D-gal in Wistar rats for a duration of 2-8 weeks. D-gal causes oxidative stress due to increased ROS, causing lipid peroxidation. Table 3 shows MDA test results observed in 2-8 weeks in each treatment group. Increased MDA activity in aging control continues until week 8 as a result of increased lipid peroxidation. D-gal can induce lipid peroxidation in the epidermis as its structure comprises phospholipids. The administration of SDP can decrease the MDA activity more than the administration of vitamin $\mathrm{E}$ and no administration at all $(\mathrm{NC})$, at each variation of the SDP dose at observations of 2-8 weeks. Based on the ANOVA test results, there were significant differences among treatment groups, the group administered with D-gal as aging control $\left({ }^{\mathrm{b}} p<\right.$ $0.05)$, and the $\mathrm{NC}\left({ }^{\mathrm{a}} p<0.05\right)$.

\section{In vitro test of antioxidant activity}

An assay of in vitro antioxidant activity of SDP was done by measuring the scavenging activity against free radicals. Based on the results of testing, the SDP scavenging activity against hydroxyl radicals $\left(\mathrm{OH}^{*}\right)$ is quite high, including strong antioxidants with $\mathrm{IC}_{50}=0.1 \mathrm{mg} / \mathrm{ml}(100 \mathrm{ppm})$; superoxide radicals $\left(\mathrm{O}_{2}{ }^{-}\right)$show the ability of low scavenging activity, including antioxidants with $\mathrm{IC}_{50}=0.174 \mathrm{mg} / \mathrm{ml}(174 \mathrm{ppm})$, as shown in Figure $1 \mathrm{a}$ and $\mathrm{b}$. The SDP shows a high performance of scavenging activity on $\mathrm{OH}^{*}$ compared with $\mathrm{O}_{2}{ }^{--}$scavenging activity. Measurement was conducted using vitamin $\mathrm{E}$ as a standard with $\mathrm{IC}_{50}=57.114 \mathrm{ppm}$ Based on $\mathrm{IC}_{50}$ values, SDP is a strong antioxidant $\left(\mathrm{IC}_{50}=50-100\right.$ $\mathrm{ppm}$ ) and an effective antiaging agent.

\section{Formation of collagen in Wistar rat skin}

Histopathological tests were carried out on the redcolored fibrocollagen matrix in Sirius Red staining. Measurement of the fibrocollagen matrix area was carried out by taking photomicrographs at $100 \times$ magnification (objective $10 \times$ ) in five different fields. The ratio of collagen in the aging control group (induced with D-gal) was lower than in the normal group. After administration of SDP at doses of 0.2 and $0.8 \mathrm{mg} / \mathrm{g} \mathrm{bw}$, an increase of collagen ratio in the skin of aging Wistar rats was higher than in the skin of normal NC and group treated with vitamin $\mathrm{E}$ as a drug control. This shows that the administration of SDP is effective in repairing collagen damage in the aging rat model. The effective dose of SDP is $0.8 \mathrm{mg} / \mathrm{g}$ bw, which can increase the amount of collagen optimally (see Fig. 2).

\section{F-AGEs formation}

The formation of F-AGEs was increased in aging Wistar rats due to D-gal induction compared with NC. D-gal induction causes an increase in ROS that can trigger the formation of AGEs

Table 1. SOD enzyme activity in various treatments with $2-8$ weeks of observation time.

\begin{tabular}{lccc}
\hline \multirow{2}{*}{ Treatment } & \multicolumn{3}{c}{ Superoksida dismutase (U/ml) } \\
\cline { 2 - 4 } & $2.2 \pm 0.056^{\mathrm{a}}$ & $\mathbf{4}$ weeks & $\mathbf{8}$ weeks \\
\hline NC & $2.3 \pm 0.056$ & $2.35 \pm 0.041$ & $2.4 \pm 0.036^{\mathrm{a}}$ \\
SDP control & $1.05 \pm 0.060^{\mathrm{b}}$ & $0.95 \pm 0.032^{\mathrm{b}}$ & $2.5 \pm 0.087$ \\
Aging control (induction D-galactose) & $2.1 \pm 0.077^{\mathrm{b}}$ & $2.25 \pm 0.062^{\mathrm{b}}$ & $2.8 \pm 1.000^{\mathrm{ab}}$ \\
Drug control (vitamin E) & $2.4 \pm 0.033^{\mathrm{b}}$ & $2.45 \pm 0.031^{\mathrm{b}}$ & $2.5 \pm 0.029^{\mathrm{ab}}$ \\
D-galactose + SDP 0.2 mg/g BW & $2.5 \pm 0.062^{\mathrm{ab}}$ & $2.55 \pm 0.041^{\mathrm{ab}}$ & $2.9 \pm 0.053^{\mathrm{ab}}$ \\
\hline D-galactoce + SDP 0.8 mg/g BW & & &
\end{tabular}

Data expressed as mean $\pm \mathrm{SD}(n=8)$

$\mathrm{SD}=$ standard deviation; $\mathrm{SDP}=S$. dimorphus polysaccharide .

${ }^{\mathrm{a}} p<0.05$ compared with the NC group.

${ }^{\mathrm{b}} p<0.05$ compared with the aging control group.

Table 2. Activity of CAT enzymes in various treatments with 2-8 weeks observation time.

\begin{tabular}{lccc}
\hline \multirow{2}{*}{ Treatment } & \multicolumn{3}{c}{ CAT (U/mI) } \\
\cline { 2 - 4 } & 2 weeks & 4 weeks & 8 weeks \\
\hline NC & $11.9 \pm 0.537^{\mathrm{a}}$ & $12.1 \pm 0.329^{\mathrm{a}}$ & $12.4 \pm 0.377^{\mathrm{a}}$ \\
SDP control & $12.2 \pm 0.329$ & $12.8 \pm 0.292$ & $13.2 \pm 0.321$ \\
Aging control (induction D-galactose) & $8.8 \pm 0.484^{\mathrm{b}}$ & $7.6 \pm 0.389^{\mathrm{b}}$ & $7.2 \pm 0.325^{\mathrm{b}}$ \\
Drug control (vitamin E) & $11.5 \pm 0.377^{\mathrm{b}}$ & $11.9 \pm 0.392^{\mathrm{b}}$ & $12.8 \pm 0.558^{\mathrm{b}}$ \\
D-galactose + SDP 0.2 mg/g BW & $11.7 \pm 0.200^{\mathrm{b}}$ & $11.9 \pm 0.192^{\mathrm{b}}$ & $13 \pm 0.389^{\mathrm{ab}}$ \\
D-galactoce + SDP 0.8 mg/g BW & $11.9 \pm 0.370^{\mathrm{b}}$ & $12 \pm 0.314^{\mathrm{b}}$ & $13.5 \pm 0.414^{\mathrm{ab}}$ \\
\hline
\end{tabular}

Data expressed as mean $\pm \mathrm{SD}(n=8)$

$\mathrm{SD}=$ standard deviation; SDP: $S$. dimorphus polysaccharide.

${ }^{\mathrm{a}} p<0.05$ compared with the NC group; ${ }^{\mathrm{b}} p<0,05$ compared with the aging control group. 
Table 3. Malondialdehid (MDA) activities on various treatments with 2-8 weeks observation.

\begin{tabular}{lccc}
\hline \multirow{2}{*}{ Treatment } & \multicolumn{3}{c}{ Malondialdehid (nmol/mL) } \\
\cline { 2 - 3 } & 2 weeks & 4 weeks & 8 weeks \\
\hline NC & $1.41 \pm 0.064$ & $1.46 \pm 0.039$ & $1.5 \pm 0.069^{\mathrm{a}}$ \\
SDP control & $1.3 \pm 0.043$ & $1.2 \pm 0.031$ & $1.1 \pm 0.072$ \\
Aging control (induction D-galactose) & $3.9 \pm 0.495$ & $4.0 \pm 0.244$ & $4.3 \pm 0.294^{\mathrm{b}}$ \\
Drug control (vitamin E) & $2.7 \pm 0.403^{\mathrm{a}}$ & $1.5 \pm 0.146^{\mathrm{b}}$ & $1.4 \pm 0.049^{\mathrm{ab}}$ \\
D-galactose + SDP 0.2 mg/g BW & $2.3 \pm 0.212$ & $2.05 \pm 0.181^{\mathrm{b}}$ & $1.5 \pm 0.082^{\mathrm{ab}}$ \\
D-galactoce + SDP 0.8 mg/g BW & $2.1 \pm 0.192$ & $1.9 \pm 0.153^{\mathrm{b}}$ & $1.05 \pm 0.182^{\mathrm{ab}}$ \\
\hline
\end{tabular}

Data expressed as mean $\pm \mathrm{SD}(n=8)$.

$\mathrm{SD}=$ standard deviation; SDP: $S$. dimorphus polysaccharide.

${ }^{\mathrm{a}} p<0.05$ compared with the NC group; ${ }^{\mathrm{b}} p<0.05$ compared with the aging control group.

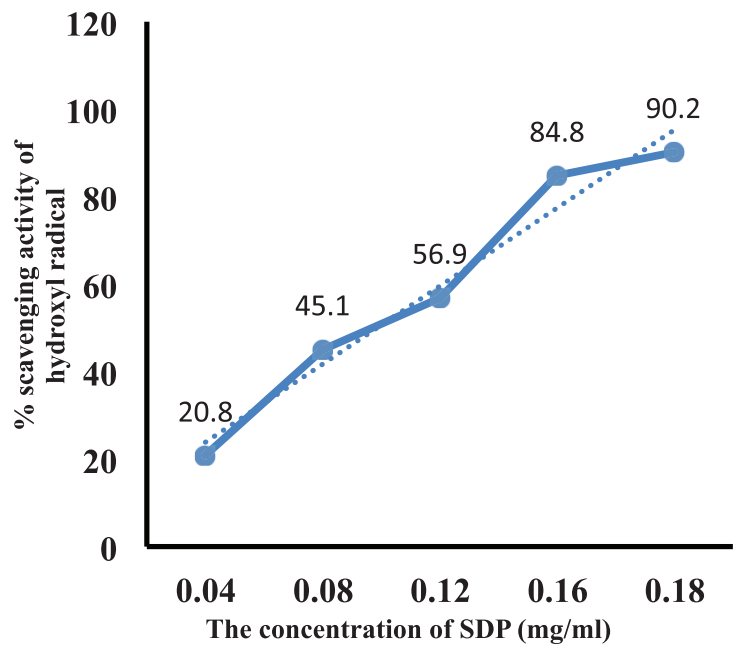

(a)

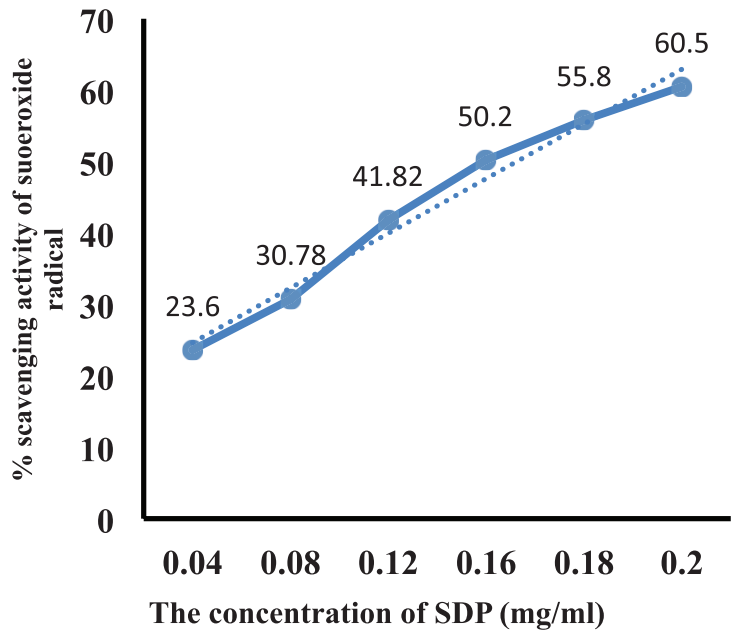

(b)

Figure 1. (a) Hydroxyl radical scavenging activity with linear regression $y=1.85+497.5 x$ and $R=0.985$; $\mathrm{IC}_{50}=0.1 \mathrm{mg} / \mathrm{ml}$. (b) Superoxide radical scavenging activity with linear regression $y=13.35+273.54 x$ and $R=0.996 ; \mathrm{IC}_{50}=0.174 \mathrm{mg} / \mathrm{ml}$.

in Wistar rats. The administration of vitamin $\mathrm{E}$ as a drug control can reduce the formation of AGEs to achieve normal conditions (like that of NC). Treatment with SDP at low doses $(0.2 \mathrm{mg} / \mathrm{g}$ bw) showed a decrease in the formation of AGE; at high doses $(0.8 \mathrm{mg} / \mathrm{g} \mathrm{bw})$, after 8 weeks of observation, the decrease in the formation of AGEs was significantly higher in rats treated with SDP than those administered with vitamin E. The administration of SDP can inhibit the formation of AGEs. This could cause a decrease in ROS because SDP has antioxidant activity. Statistical analysis (ANOVA at $p<0.05$ ) showed a significant difference in each treatment group for aging control (group treated with D-gal).

\section{Histopathology of Wistar rat skin tissue}

Photomicrographs of the rat skin showed a difference in the deposition of the fibrocollagen matrix among treatment groups. The red fibrinogen matrix on Sirius Red staining on the skin of the aging Wistar rat due to D-gal induction (Fig. 3b) shows a thinner dermis with lower matrix deposition accompanied by lower collagen deposition compared to that in NC (Fig. 3A).

In the $\mathrm{NC}$, fibrocollagen matrix in the dermis between the adnexa was clearly visible and colored red by Sirius Red. The provision of vitamin $\mathrm{E}$ as a drug control (Fig. 3c) in rats aging due to D-gal induction shows that the group treated with vitamin E could increase matrix deposition marked by a thicker collagen matrix than $\mathrm{NC}$ and aging control (group treated with D-gal). Treatment with SDP $(0.2 \mathrm{mg} / \mathrm{g} \mathrm{bw})$ in aging rats increased matrix deposition, which was more evident in the treatment group with high doses of SDP $(0.8 \mathrm{mg} / \mathrm{g} \mathrm{bw})$, with thicker fibrocollagen matrix, diffuse, and dense (see Fig. $3 \mathrm{~d}$ and e). Thus, SDP is useful as an antiaging agent in rats aging due to the induction of D-gal, as it repairs damage to the fibrocollagen matrix and stimulates the increase of collagen synthesis.

\section{DISCUSSION}

\section{Enzyme activity of SOD, CAT, and MDA}

The induction of D-gal can cause overall aging in various organ systems. Xu (1985) reported that mouse induced by D-gal for 6 consecutive weeks can increase galactose in their bodies, which cause accelerated aging in mouse; he found remarkable signs of aging in ICR mouse after being injected with D-gal in the retrobulbar for 8 weeks. D-gal-induced mice have been used as animal models in aging research or antiaging pharmacology (Wei et al., 2005). The aldose reductase enzyme plays a role in turning galactose into galactitol, a compound that cannot be metabolized 


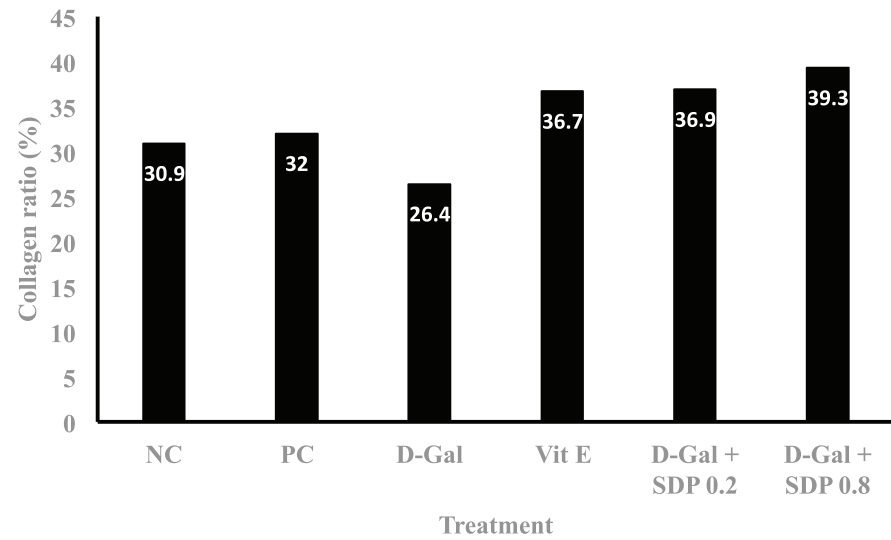

Figure 2. Collagen ratio at treatment, NC, PC, D-gal (D-gal induction for aging), Vit E (drug control), D-gal + SDP $0.2 \mathrm{mg} / \mathrm{g}$ BW (aging treated with low-dose $S$. dimorphus polysaccharide), and D-gal + SDP $0.8 \mathrm{mg} / \mathrm{g} \mathrm{BW}$ (aging treated with high-dose $S$. dimorphus polysaccharide).

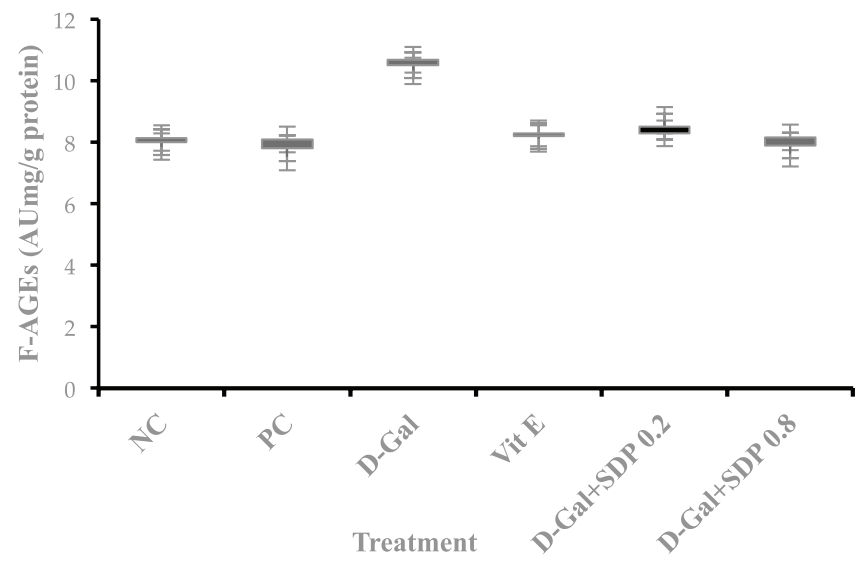

Figure 3. F-AGEs expressed in $\mathrm{AU} \mathrm{mg} / \mathrm{g}$ protein (mean $\pm \mathrm{SD}$ of eight rats) and formation of fluorescent-advanced glycation end products at treatment; NC, PC, D-gal (D-gal induction for aging), Vit E (Drug control), D-gal + SDP 0.2 $\mathrm{mg} / \mathrm{g} \mathrm{BW}$ (aging treated with low-dose polysaccharide $S$. dimorphus), and D-gal + SDP $0.8 \mathrm{mg} / \mathrm{g}$ BW (aging treated with high-dose SDPs). Statistical analysis (ANOVA) showed a significant difference in aging control (D-gal) at $p<0.05$.

by the body and gets accumulated in cells, thereby causing osmotic pressure changes; this can cause cell swelling, cell dysfunction, and eventually causes aging (Ye et al., 2014).

The induction of D-gal causes aging in Wistar rats due to increased ROS leading to oxidative stress. When the level of ROS exceeds cell's defense mechanisms, the production of ROS during environmental stress can pose a threat to cells, resulting in lipid peroxidation, protein oxidation, nucleic acid damage, enzyme inhibition, and ultimately cell death (Sharma and Dubey, 2005; Srivastava and Dubey, 2011; Verma and Dubey, 2003). D-gal induction causes cell death in the skin of Wistar rats because an increase in ROS triggers aging faster than in normal conditions. Oxidative stress due to D-gal induction decreases endogenous antioxidant activity (SOD and CAT) in Wistar rats, as shown in Tables 1 and 2. SOD enzymes play a role in catalyzing the conversion of superoxide to oxygen and hydrogen peroxide; subsequently, CAT converts hydrogen peroxide into oxygen and water. Superoxide anions are products aimed specifically at enzyme signaling; they are by-products of several metabolic processes that are caused by SOD activity controlling the level of various ROS (Wang et al., 2018).

Chemically, the SOD activity accelerates the reaction of superoxide anions $\left(\mathrm{O}_{2}^{-}\right)$by forming hydrogen peroxide $\left(\mathrm{H}_{2} \mathrm{O}_{2}\right)$ and oxygen (Hayyan et al., 2016). SOD, CAT, and GSH-Px are the three main endogenous protein antioxidants with enzymatic activity, which are the first line of defense against oxidative stress on the body (Aguilar et al., 2016). The administration of SDPs can enhance the effectiveness of endogenous antioxidant SOD and CAT to near-normal values; it is better than giving vitamin $\mathrm{E}$, since SDP as an antioxidant can scavenge superoxide and hydroxyl free radicals. SDP can inhibit oxidative stress and MMP expression, causing SOD and CAT to increase. Excessive oxidative stress or inflammatory response can activate MMP because oxidative stress increases MMP regulation, including MMP-1, MMP-3, MMP-9, and MMP-13, through binding of AP-1 to MMPs and proinflammatory cytokines; it also increases MMPs to regulate and decrease elastin collagen fibers (Pittayapruek et al., 2016).

The development of MMP inhibitors is a promising antiaging strategy. Wrinkles in the skin form due to the breakdown of extracellular matrix proteins through fragmentization of collagen and MMP secretion (Naylor et al., 2011). Natural polysaccharides from Psudoelteromonas sp., low-molecular-weight fucoidan, function as antiaging and anti-inflammatory agents, since they can reduce connective tissue damage by inhibiting MMP activity and increasing collagen synthesis (Kim et al., 2018). Native fucoidan modulates MMP and fibroblast expression in humans (Moon et al., 2009). Natural polysaccharides extracted from Porphyridium have strong antiaging characteristics that have shown significant inhibitory activity of both hyaluronidase and elastase enzymes, which play an important role in skin aging (Kenny et al., 2012).

In this study, owing to the induction of D-gal, a significant increase in MDA and accelerated aging in the skin of Wistar rats used as animal models were observed at periods of 2, 4, and 8 weeks compared with those of NC and drug control (vitamin E). D-gal induction can cause oxidative stress due to increased ROS, which can induce lipid peroxidation and epididymis as the structure consists of phospholipids. Lipid peroxidation due to D-gal induction triggers an increase in ROS so that MDA levels increase. Increased ROS and decreased endogenous antioxidant activity (SOD and CAT) can disrupt the balance of the reductionoxidation reaction (redox), causing oxidative stress.

Hydroxyl radicals $\left(\mathrm{OH}^{\circ}\right)$, produced by $\mathrm{H}_{2} \mathrm{O}_{2}$ at high levels due to ROS, attack polyunsaturated fatty acids in membranes, forming reactive carbon radicals that react with oxygen to form peroxyl radicals. This product results in the self-amplifying generation of lipid peroxide, which causes extensive damage and, ultimately, the disintegration of the membrane. Decomposed lipid peroxides form various aldehydes, including MDA, which are used as analytic markers of lipid peroxidation (Packer et al., 2013). Prolonged oxidative stress results in ROS, which can damage the lipid membrane of the bilayer phospholipid component of the cell wall, causing cell death to continue damaging the tissue around the cell (Del Rio et al., 2005). D-gal reacts with macromolecules such as lipids, proteins, and DNA without enzymatic reactions. The end result of this reaction is the formation of AGEs, which can be significantly accelerated by oxidative stress and trigger the 

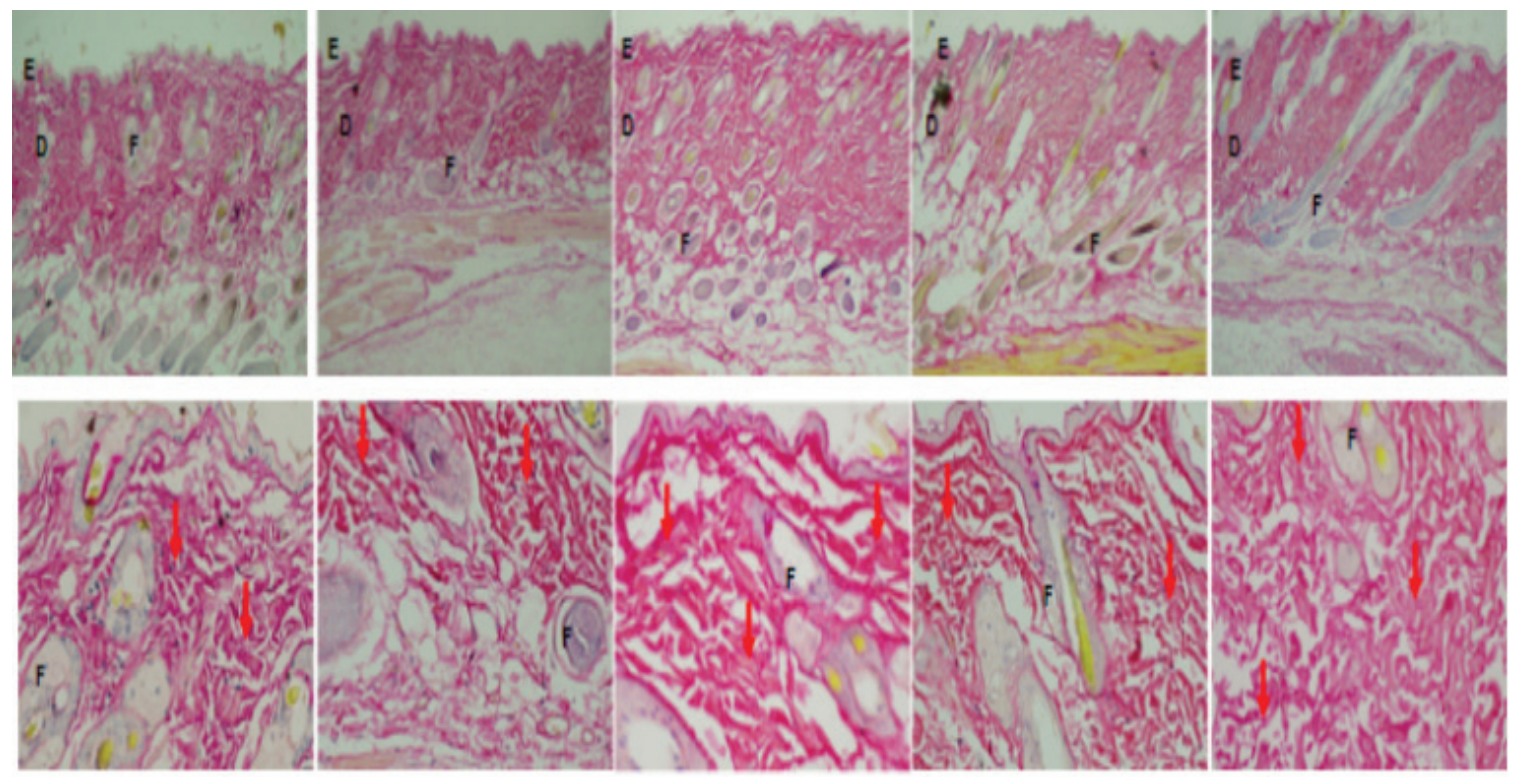

A

B

C

D

$\mathbf{E}$

Figure 4. Comparison of fibrocollagen matrix deposition in animal skins, control, and treatment. The fibrocolagen matrix is colored red in Sirius Red staining. (A) NC, (B) aging control (D-gal), (C) Vit E (drug control), (D) treatment with SDP $0.2 \mathrm{mg} / \mathrm{g} \mathrm{BW}$, and (E) treatment with SDP $0.8 \mathrm{mg} / \mathrm{g} \mathrm{BW}$. Caption index in the picture; epidermis (E), dermis (D), hair follicles (F), and collagen bundle $(\downarrow)$ with $40 \times$ and $100 \times$ magnification.

occurrence of lipid peroxidation reactions as well as an increase in MDA levels (Ahmed, 2005; Gkogkolou and Bohm, 2012).

\section{F-AGEs formation}

The administration of SDP to aging Wistar rats can reduce ROS, since SDP as an antioxidant can scavenge $\mathrm{OH}^{\cdot}\left(\mathrm{IC}_{50}\right.$ $=0.1 \mathrm{mg} / \mathrm{ml})$ and $\mathrm{O}_{2}^{-}\left(\mathrm{IC}_{50}=0.174 \mathrm{mg} / \mathrm{ml}\right)$, thereby inhibiting the formation of $\mathrm{AGE}$ and lipid peroxidation; this reduces MDA levels. Cells have special receptors for AGE (RAGE), where the stimulation of these receptors leads to the activation of transcription factors to increase the transcription of proinflammatory genes (Bierhaus et al., 2005). RAGE is expressed in mRNA and also in terms of the level of protein in fibroblasts and keratinocytes, and the expression is increased in sun-exposed skin, causing skin aging (Lohwasser et al., 2006). Since AGE can react with a variety of biomolecules, its formation leads to collagen cross-linking, which decreases flexibility (Prasad et al., 2012; Yamagishi et al., 2012). AGE, when accumulated in cells, can accelerate the physiological aging process (Chen et al., 2018). D-gal induction in treated Wistar rats caused a decreased collagen ratio compared with that in normal and drug controls (group treated with vitamin E); this was owing to a degradation of the fibrocollagen matrix, resulting in the aging of Wistar rats.

The aging process was driven by the reduction of ROS due to the induction of D-gal, resulting in the activation of MMPs and degradation resulting from extracellular matrix components, especially collagen and elastic fibers. These changes in the extracellular matrix (ECM) cause the appearance of fine wrinkles; in the dermis extracellular matrix, disorders play an important role in intrinsic and extrinsic aging. Wrinkles are caused by a reduction in collagen, elastic fibers, and hyaluronic acid. Enzymes in the ECM are responsible for processing elastic fibers, collagen, and proteoglycans (Ritz-Timme et al., 2003; Shapiro et al., 1991). Elastic fibers are structures that are rich in fibrillin, microfibrils, glycoproteins, elastin, and proteins (Kielty et al., 2002). These glycoproteins are interconnected through hyaluronic acid and build up skin tissue (Naylor et al., 2011). AGE can react with a variety of biomolecules; for example, they can result in the formation of collagen cross-bonds, which causes a decrease in skin flexibility (Lal et al., 2002). Owing to the induction of fibroblast activation, collagen cross-linking and metalloproteinase (MMP 1, 2, and 9) production increase, and AGEs greatly affect the dermis (Pageon et al., 2007). The administration of SDP in aging Wistar rats increases the collagen ratio since SDP inhibits the activation of MMPs and enzymes in an ECM, namely elastase and collagenase, which causes damage to collagen and reduces skin elasticity; this is because SDP can reduce ROS so that the synthesis of collagen can be stimulated by the SDP.

\section{Histopathology of Wistar rat skin tissue}

There were differences in the deposition of the fibrocollagen matrix among treatment groups. In normal mice $(\mathrm{NC})$, the fibrocollagen matrix was seen in the dermis between adnexa. Rat aging due to D-gal induction displayed visible lower collagen matrix deposition with a thinner dermis accompanied by lower collagen deposition than that of NC (Liao et al., 2016). The dermis provides structural support for skin blood vessels; its depletion causes structural changes in the skin.

In aging skin, fragmentation of the skin collagen matrix occurs, as a result of the action of specific enzymes (MMPs) and destroys the structural integrity of the dermis, triggered by the induction of D-gal. Fibroblasts functions to produce and regulate collagen matrices that cannot attach to fragmented collagen. Loss 
of attachment prevents fibroblasts from receiving mechanical information and leads to collapse (Fisher et al., 1996), resulting in lower collagen deposition. In old skin, collapsed fibroblasts cause decreased levels of collagen and increased levels of collagendegrading enzymes. In aging rats given the drug (vitamin E), collagen deposition appears thicker than in normal and aging control. This is due to vitamin E, which acts as an antidote to free radicals (ROS) so as to prevent the occurrence of AGE and inhibit the activity of MMP-1; this causes collagenase to specifically decompose certain collagens or other proteins in the dermis ECM (Lapiere, 2005; Sanz, 2016). MMPs are responsible for the physiological degradation of various ECM proteins (PageMcCaw et al., 2007). Collagen fragmentation in skin aging is a consequence of the physical and functional interactions between fibroblasts and the skin matrix as well as the accumulation of fragmented collagen which causes changes in the appearance of the skin. Only interstitial collagenase (MMP-1) is involved in the replacement of normal skin collagen, of the four collagenases expressed in humans (Kenny et al., 2012). In healthy young skin, MMP-1 expression is very low.

SDP provides an illustration of increased collagen matrix deposition; at high doses, collagen deposition caused by it is more higher and slightly higher than that caused by vitamin E. Excessive D-gal administration disrupts the synthesis of the collagen matrix in the body including the dermis; if there is fat accumulation, the subcutis accompanying the collagen deposition of the skin can be lower, marked by thin skin and sagging/reduced skin elasticity. This is what happened in the aging control group in this study. With the administration of vitamin $\mathrm{E}$ as an antioxidant, an increase in ROS can be prevented. The ROS free radical antidote can prevent lipid peroxidase so that no decomposition of fat or ECM including skin collagen matrix occurs; this may be the basis for increased collagen matrix deposition and bundle in vitamin E administration (Dikalov and Harisson, 2014).

The administration of SDP contains beta-glucan monomers, which have antioxidant activities with a high ability to ward off free radicals (ROS); these monomers also have an effect like that of vitamin $\mathrm{E}$ in increasing matrix deposition and collagen bundle at higher polysaccharide doses, activity its antioxidants higher compared to vitamin $\mathrm{E}$ because polysaccharides have complex ingredients such as galacturonic acid, N-acetyl-dglucosamine, and compound hyaluronic acid in addition to antioxidants. This apparently can encourage higher collagen matrix synthesis than that of vitamin E. Natural polysaccharides have shown significant inhibitory activity of the two enzymes that play an important role in the aging process, namely hyaluronidase and elastase enzymes (Kenny et al., 2012).

\section{CONCLUSION}

The administration of SDPs can overcome premature aging due to D-gal induction by increasing the activity of SOD and CAT enzymes and reducing MDA to inhibit oxidative stress. SPD can inhibit the formation of AGEs and activation of the enzyme MMP, which accelerates the physiological aging process. SPD can stimulate collagen synthesis in the dermis tissue of the skin, thereby increasing skin firmness and elasticity. Thus, SDP is a better antiaging agent for the skin than vitamin $\mathrm{E}$.

\section{ACKNOWLEDGMENTS}

The authors are grateful for the PNBP funding support from the Faculty of Mathematics and Natural Sciences, Andalas University, according to Research Contract Number 21/ UN.16.03.D/PP/FMIPA/2019.

\section{ETHICS COMMITTEE}

This research was conducted in accordance with the principles expressed in the Declaration of Helsinki on the use of experimental animals. An ethics permit was obtained from the Research Ethics Committee of the Faculty of Medicine, Andalas University (registration number 258/KEP/FK/2019).

\section{CONFLICT OF INTEREST}

The authors declare no conflict of interest.

\section{AUTHOR CONTRIBUTIONS}

All authors made substantial contributions to conception and design, acquisition of data, or analysis and interpretation of data; took part in drafting the article or revising it critically for important intellectual content; agreed to submit to the current journal; gave final approval of the version to be published; and agree to be accountable for all aspects of the work. All the authors are eligible to be an author as per the international committee of medical journal editors (ICMJE) requirements/guidelines.

\section{PUBLISHER'S NOTE}

This journal remains neutral with regard to jurisdictional claims in published institutional affiliation.

\section{REFERENCES}

Aguilar TAF, Navarro BCH, Pérez JAM. Endogenous antioxidants: a review of their role in oxidative stress. In: Gonzalez JAM, Gonzalez AM, Santillan EOM, (eds.). A master regulator of oxidative stress - the transcription factor Nrf2. IntechOpen, Vienna, Austria, 2016; doi: $10.5772 / 65715$

Ahmed N. Advanced glycation endproducts-role in pathology of diabetic complications. Diabetes Res Clin Pract, 2005; 67:3-21.

Armaini A, Dharma A, Salim M. The nutraceutical effect of Scenedesmus dimorphus for obesity and nonalcoholic fatty liver diseaselinked metabolic syndrome. J Appl Pharm Sci, 2020; 10(05):070-6.

Bierhaus A, Humpert PM, Morcos M, Wendt T, Chavakis T, Arnold B, Stern DM, Nawroth PP. Understanding rage, the receptor for advanced glycation end products. J Mol Med, 2005; 83:876-86.

Charan J, Kantharia, ND. How to calculate sample size in animal studies? J Pharmacol Pharmacother, 2013; 4(4):303-6; doi:10.4103/0976500X.119726

Chen P, Chen F, Zhou B. Antioxidative, anti-imflammatory and anti-apoptotic effect of ellagic acid in liver and brain of rats treated by D-galactose. Sci Rep, 2018; 8(1):1645.

Chu WL, Lim YW, Radhakrishnan AK, Lim PE. Protective effect of aqueous extract from Spirulina platensis against cell death induced by free radicals. BMC Complement Altern Med, 2010; 10:53-63.

Del Rio D, Stewart AJ, Pellegrini N. A review of recent studies on malondialdehyde as toxic molecule and biological marker of oxidative stress. Nutr Metab Cardiovasc Dis, 2005; 15(4):316-28.

Dikalov SI, Harrison DG. Methods for detection of mitochondrial and cellular reactive oxygen species. Antioxid Redox Signal, 2014; 20:372-82.

Fisher GJ, Datta SC, Talwar HS, Wang ZQ, Varani J, Kang S, Voorhees JJ. Molecular basis of sun induced premature skin ageing and retinoid antagonism. Nature, 1996; 379:335-9. 
Gkogkolou P, Bohm M. Advanced glycation end products key players in skin aging? Derm Endocrinol, 2012; 4:259-70.

Hayyan M, Hashim MA, Al Nashef IM. Superoxide Ion generation and chemical implications. Chem Rev, 2016; 116:3029-85; doi:10.1021/acs.chemrev.5b0040/

Hwang PA, Chien SY, Chan YL, Lu MK, Wu CH, Kong ZL, Wu CJ. Inhibition of lipopolysaccharide (LPS)-inducedinflammatory responses by Sargassum hemiphyllumsulfated polysaccharide extract in RAW 264.7 macro-phage cells. J Agric Food Chem, 2011; 59:2062-8.

Kenny C, Bayona D, Sandra M, Navarro G, Andrés DL, Coorado JR, Atehortúa LG, Martínez AM. Activity of sulfated polysaccharides from microalgae Porphyridium cruentum over degenerative. mechanisms of the skin. Int J Sci Adv Technol, 2012; 2(8):85-92; http//www.ijsat.com85

Kielty CM, Sherratt MJ, Shuttleworth CA. Elastic fibers. J Cell Sci, 2002; 115:2817-28.

Kim YI, Oh WS, Song PH, Yun S, Kwon YS, Lee YJ, Ku SK,ISong, CH, Oh TH. Anti-photoaging effects of low molecular-weight fucoidan on ultraviolet B-irradiated mice. Mar Drugs, 2018; 16(1-13):286; doi: $10.3390 / \mathrm{md} 16080286$

Kogan G, Soltés L, Stern R, Gemeiner P. Hyaluronic acid: a natural biopolymer with a broad range of biomedical and industrial applications. Biotechnol Lett, 2007; 29:17-25.

Lal MA, Brismar H, Eklof AC, Aperia A. Role of oxidative stress in advanced glycation end product-induced mesangial cell activation. Kidney Int, 2002; 61:2006-14.

Lapiere CM. Tadpole collagenase, the single parent of such a large family. Biochimie, 2005; 87(3-4):243-7.

Li SS, Liu M, Zhang C, Tian CY, Wang XX, Song XL, Jing HJ, Gao Z, Ren Z, Liu W, Zhang J, Jia L. Purifification, in vitro antioxidant and in vivo anti-aging activities of soluble polysaccharides by enzyme-assisted extraction from Agaricus bisporus. Int J Biol Macromol, 2018; 109:457-66.

Liao CH, Chen BH, Chiang HS, Chen CW, Chen MF, Ke CC, Wang YY, Lin WN, Wang CC, Lin YH. Optimizing a male reproductive aging mouse model by D-galactose injection. Int J Mol Sci, 2016; 17:1-10.

Lohwasser C, Neureiter D, Weigle B, Kirchner T, Schuppan D. The receptor for advanced glycation end products is highly expressed in the skin and upregulated by advanced glycation end products and tumor necrosis factor-alpha. J Investig Dermatol, 2006; 126:291-9.

Mc Auley MT, Guimera AM, Hodgson D, Mcdonal N, Mooney KM, Morgan1 AE, Proctor CJ. Modelling the molecular mechanisms of aging. Biosci Rep, 2017; 37:160-77.

Moon HJ, Lee SH, Ku MJ, Yu BC, Jeon MJ, Jeong SH, Stonik VA, Zvyagintseva TN, Ermakova SP, Lee YH. Fucoidan inhibits UVBinduced MMP-1 promoter expression and down regulation of type I procollagen synthesis in human skin fifibroblasts. Eur J Dermatol, 2009; 19:129-34.

Naylor EC, Watson RE, Sherratt MJ. Molecular aspects of skin ageing. Maturitas, 2011; 69:249-56.

Packer L, Cadenas E. Hydrogen peroxide and cell signaling. Part B, Elsevier Science \& Technology, San Diego, CA, Vol 5, pp 327-76, 2013.

Page-McCaw A, Ewald AJ, Werb Z. Matrix metalloproteinases and the regulation of tissue remodelling. Nat Rev Mol Cell Biol, 2007; 8(3):221-33.

Pageon H, Bakala H, Monnier VM, Asselineau D. Collagen glycation triggers the formation of aged skin in vitro. Eur J Dermatol, 2007; 17:12-20.

Pittayapruek P, Meephansan J, Prapapan O, Komine M, Ohtsuki M. Role of matrix metalloproteinases in photoaging and photocarcinogenesis. Int J Mol Sci, 2016; 17:868.
Prasad A, Bekker P, Tsimikas S. Advanced glycation end products and diabetic cardiovascular disease. Cardiol Rev, 2012; 20:177-83.

Ritz-Timme S, Laumeier I, Collins MJ. Aspartic acid racemization evidence for marked longevity of elastin in human skin. Br J Dermatol, 2003; 149:951-9.

Sanz A. Mitochondrial reactive oxygen species do they extend or shorten animal lifespan. Biochim Biophys Acta, 2016; 1857:1116-26.

Schieber M, Chandel NS. ROS function in redox signaling and oxidative stress. Curr Biol, 2014; 24:453-62.

Shapiro SD, Endicott SK, Province MA, Pierce, JA, Campbell EJ. Marked longevity of human lung parenchymal elastic fibers deduced from prevalence of d-aspartate and nuclear weapons-related radiocarbon. J Clin Invest, 1991; 87:1828-34.

Sharma P, Dubey RS. Drought induces oxidative stress and enhances the activities of antioxidant enzymes in growing rice seedlings. Plant Growth Regul, 2005; 46(3):209-21.

Srivastava S, Dubey RS. Manganese-excess induces oxidative stress, lowers the pool of antioxidants and elevates activities of key antioxidative enzymes in rice seedlings. Plant Growth Regul, 2011; 64:116.

Thomas NV, Kim SK. Beneficial effects of marine algalcompounds in cosmeceuticals. Mar Drugs, 2013; 11:146-64.

Verma S, Dubey RS. Lead toxicity induces lipid peroxidation and alters the activities of antioxidant enzymes in growing rice plants. Plant Sci, 2003; 164(4):645-55.

Wang HMD, Chen CC, Huynh P, Chang JS. Exploringthe potential of using algae in cosmetics. Bioresour Technol, 2015; 184:355-62.

Wang Y, Branicky R, Alycia Noë A, Hekimi S. Superoxide dismutases dual roles in controlling ROS damage and regulating ROS signaling. J Cell Biol, 2018; 217(6):1915-28.

Wei H, Song Q, Li L, Chu JAH, Li W. Behavioural study of the D-galactose induced aging model in C57BL/6J mice. Behav Brain Res, 2005; 15(7):245-51.

Xu FB. Sub-acute toxicity of D-galactose. In Proceedings of the Second National Conference on Aging Research, Herbin, China, 1985

Yamagishi S, Maeda S, Matsui T, Ueda S, Fukami K, Okuda S. Role of advanced glycation end products (ages) and oxidative stress in vascular complications in diabetes. Biochim Biophys Acta Gen Subj, 2012; 1820:663-71

Ye Y, Jia RR, Tang L, Chen F. In vivo antioxidant and anti-skinaging activities of ethyl acetate extraction from idesia polycarpa defatted fruit residue in aging mice induced by D-galactose. Evid Based Complement Altern Med, 2014; 2014:12; doi:10.1155/2014/185716

Zhao HJ, Li J, Zhang JJ, Wang XX, Hao L, Jia L. Purifification, in vitro antioxidant and in vivo anti-aging activities of exopolysaccharides by Agrocybe cylindracea. Int J Biol Macromol, 2017; 102:351-7.

Zhong Q, Wei B, Wang S, Ke S, Chen J, Zhang H, Wang H. The antioxidant activity of polysaccharides derived from marine organisms: an overview. Mar Drugs, 2019;17:674; doi:10.3390/md17120674

How to cite this article:

Armaini A, Imelda I. The protective effect of Scenedesmus dimorphus polysaccharide as an antioxidant and antiaging agent on aging rat model induced by D-galactose. J Appl Pharm Sci, 2021; 11(05):054-063. 


\section{APPENDIX}

Table 1. Composition of the polysaccharide $S$. dimorphus.

\begin{tabular}{lc}
\hline Component & Yield (\%) \\
\hline D-Fructose & 16.2 \\
D-Mannose & 10.5 \\
D-Glucose & 36.7 \\
L-Arabinose & 0.9 \\
D-Galactose & 7.8 \\
Glucuronic acid & 1.6 \\
Galacturonic acid & 11.8 \\
-Glucan & 21.8 \\
Total carbohydrate & 21.5 \\
\hline
\end{tabular}

\section{TABLE DESCRIPTION}

Measurement of D-fructose, D-glucose, and D-manose using the Megazyme Assay Kit Product code K-MANGL at a wavelength of $340 \mathrm{~nm}$.

Measurement of L-arabinose and D-galactose using the Megazyme Assay Kit Product code K-ARGA at a wavelength of $340 \mathrm{~nm}$.

Measurement of D-galacturonic acid and D-glucuronic acid using Megazyme Assay Kit Product code K-URONIC at a wavelength of $340 \mathrm{~nm}$.

Beta-glucan measurement uses the Megazyme Assay Kit Product code K-BGLU at a wavelength of 510 .

Total carbohydrates were determined by colorimetric method using phenol sulfate measured at a wavelength of $490 \mathrm{~nm}$. 